\title{
Trends in landscape research and landscape planning: implications for PhD students
}

\author{
Gunther Tress", Bärbel Tress", Gary Fry ${ }^{\# \#}$ and Marc Antrop ${ }^{\# \#}$
}

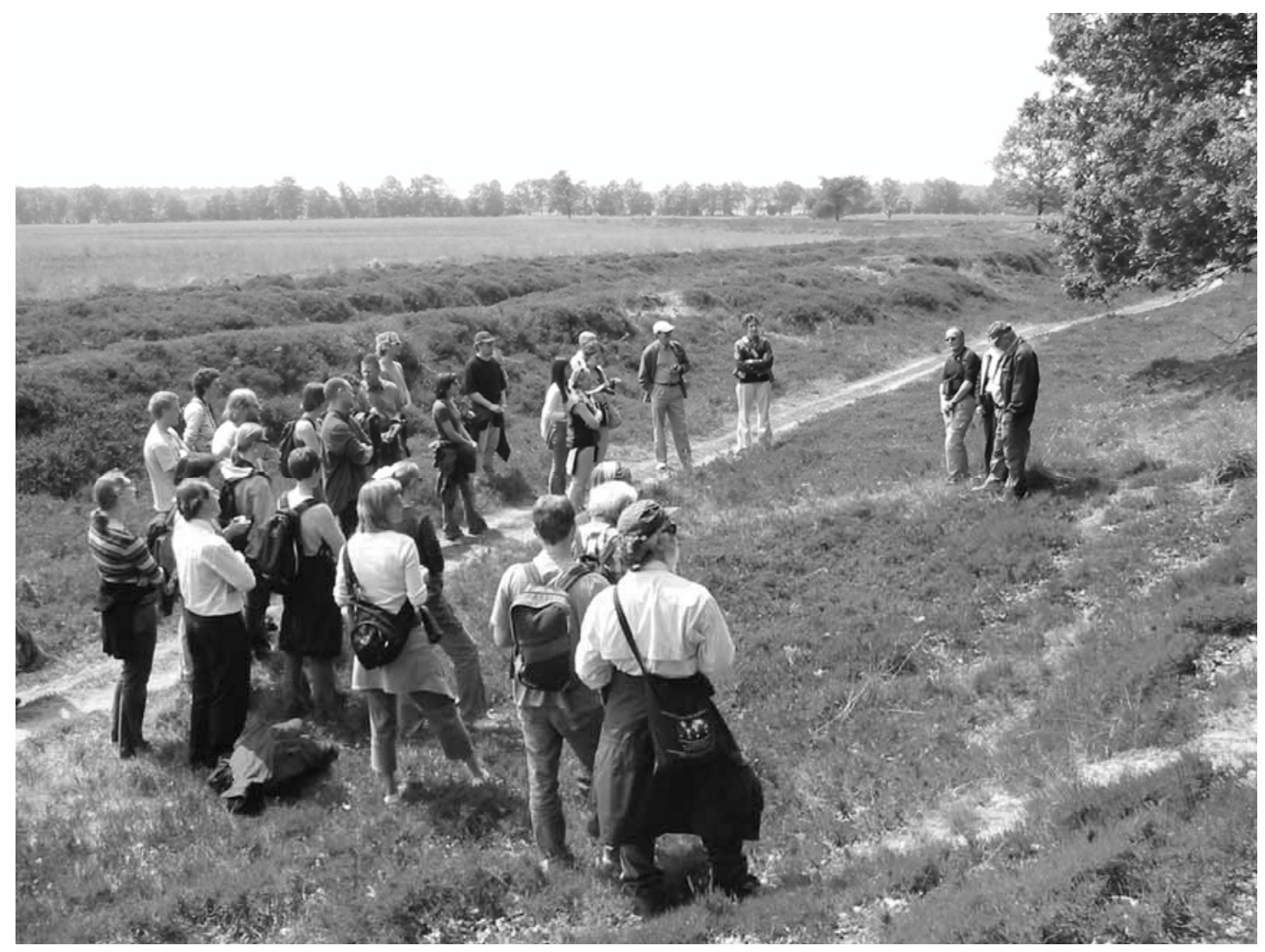

\begin{abstract}
This chapter introduces the contents of the book through an analysis of current trends in landscape research and landscape planning and a discussion of the consequences of these trends for $\mathrm{PhD}$ students. Landscape research has become more and more applied and involves a broad variety of experts from various disciplines. Societal, political and intellectual changes have led to an increase in integrative landscape projects. Many of these projects involve $\mathrm{PhD}$ students in integrative

\footnotetext{
\# Land Use Planning Group, Department of Environmental Sciences, Wageningen University, Generaal Foulkesweg 13, 6703 BJ Wageningen, The Netherlands. E-mail: tress@tress.cc, http://www.tress.cc \#\# Institute of Landscape Planning, Norwegian University of Life Sciences, P.O. Box 5029, N-1432 Ås, Norway. E-mail: gary.fry@umb.no

\#\#\# Ghent University, Geography Department, Krijgslaan 281 S8, B-9000 Ghent, Belgium. E-mail: marc.antrop@ugent.be
} 
landscape research. To gain an insight into the way $\mathrm{PhD}$ students cope with the challenges of integrative research, we used a questionnaire survey to ask $30 \mathrm{PhD}$ students attending a course on integrative landscape research about their experiences of working in integrative research. From their answers and discussions during the course, we identified six key challenges for $\mathrm{PhD}$ students in integrative research projects: (i) defining concepts related to integrative research; (ii) coping with epistemological differences across knowledge cultures; (iii) coping with high expectations of the results and products of integrative research; (iv) involving stakeholders and the general public; (v) overcoming organizational barriers; and (vi) communicating and publishing successfully.

Keywords: postgraduates; interdisciplinary; transdisciplinary; integrative research; barriers to integration

\section{Introduction: From landscape research to landscape planning}

This chapter introduces current trends and developments in landscape research and landscape planning in order to identify the societal and academic context for an increasing number of $\mathrm{PhD}$ projects. We discuss the consequences and challenges of these trends for postgraduate and $\mathrm{PhD}$ students and relate these to the structure and content of this book.

Landscape research is still a young field of research but is increasingly attracting researchers from various disciplinary and academic backgrounds. The concept of landscape is not new and has been studied and debated many times (Bender 1993; Muir 1999; Antrop 2000; Tress and Tress 2001; Cosgrove 2003). The subject of study, the landscape, is of interest to many fields of research. However, differences can be made between research taking place in landscapes and research on landscapes.

To clarify our understanding, we propose definitions of landscape, landscape research and landscape planning. We follow the European Landscape Convention and define landscapes as areas, as perceived by people, whose character is the result of the action and interaction of natural and/or human factors (Council of Europe 2000). Landscape research investigates problems and perspectives related to different uses and perceptions of landscapes and the different interests of a wide range of actors. Landscape research also analyses the complex relationships between spatial systems and these actors. By landscape planning we mean the primary attempt to influence the spatial organization of landscapes. This is achieved by making trade-offs between different needs, demands, values and land uses. Landscape planning deals with the difficult question of how to solve land-use conflicts between different interest groups and proposes strategies for future development and organization of a landscape. The European Landscape Convention describes landscape planning as a strong forwardlooking action to enhance, restore or create landscapes (Council of Europe 2000).

Since the 1990s, interest in landscape research has increased and more funding has been available for landscape studies (Tress, Tress and Fry 2005b). Along with the increasing number of landscape research projects, other demands grew. Research projects are increasingly required to have a more applied profile and relevance for society, especially in relation to the development of landscape policy and planning. This is not unique to landscape research but valid for many fields of research related to the management of natural and cultural resources. As a field with a focus on spatial development, landscape research is expected to contribute to solving the growing number of land-use conflicts and environmental problems in landscapes at local, regional, national and international levels. Projects have got bigger in terms of budget 
and numbers of researchers involved. Research networks have also grown and they expand across national borders. The increasing complexity of landscape management problems was the main argument used to involve more disciplines in projects established to investigate and solve these problems. As a result, problem-solving and the social relevance of landscape research gained greater importance. The involvement of a broader spectrum of disciplines and expert knowledge in a project promised a greater success in solving landscape problems. Landscape researchers discovered the limitations of disciplinary ways of research and problem-solving and increased their cooperation and interaction with disciplines and fields working on similar topics (Toth 1988; Sancar 1993; Naveh 1995; Di Castri 1997; Hobbs 1997; Antrop 2000; Décamps 2000; Pickett, Cadenasso and Grove 2004).

These societal, political and intellectual changes led to an increase in integrative (i.e., interdisciplinary and transdisciplinary) landscape projects, where the cooperation of disciplines across their disciplinary boarders and the involvement of stakeholders and end-users of research results were involved. Interdisciplinarity means the involvement of several unrelated academic disciplines in a way that forces them to cross subject boundaries to create new knowledge and theory and solve a common research goal. Transdisciplinarity means the integration of both academic researchers from different unrelated disciplines and non-academic participants to research a common goal and create new knowledge and theory (Tress, Tress and Fry 2005a; in press). Integrative research efforts were seen as the most suitable approaches to cope with a variety of problems related to landscapes. Integrative landscape research teams include researchers from geography, philosophy, planning, architecture, ecology, law, history, landscape ecology, biology, sociology, psychology, archaeology and others. Expectations from society, funding bodies and researchers towards the outcome and added value of integration are extensive and ambitious.

Integrative landscape research is no easy task, and researchers, research managers and research councils have to struggle with the operationalization of integration. Thus, integrative research is both a challenge and an opportunity for landscape research and planning. It is a challenge because the overlap between landscape research and landscape planning increases and risks blurring the boundaries between research and application (Fry, Tress and Tress 2004; Tress, Tress and Fry 2005b). It is an opportunity because the broad range of different expertises involved makes integrative approaches more likely to find new and innovative approaches to solving environmental problems. These may include problems related to environmental pollution, nature conservation, urban sprawl, rural development, health issues, tourism, recreation, cultural heritage, hazard research and others. These problems are neither new nor specific landscape problems. However, they open great future opportunities for landscape researchers and landscape planners because of the problems' spatial components, their integrated, complex nature, and the advances already made in integrative research.

Today, a growing number of $\mathrm{PhD}$ students are involved in integrative landscape research. They are stimulated by the prospect of merging knowledge communities with expertise on landscapes in order to gain better understanding of their research subjects. At the same time, theory and methods for use in integrative landscape research are still evolving and mostly at an early phase of development. As with the early phases of any academic realm, there exist many tensions and conflicts over the choice of appropriate epistemological models.

The landscape concept itself and the wish to integrate is often the key motivation for integration in $\mathrm{PhD}$ projects. In this chapter, we identify some of the challenges that 
PhD students and postgraduates face when involved in integrative landscape research. The contributions in this book aim at providing help to cope with these challenges and illustrate how integrative research concepts can successfully be applied.

We have chosen the book title "From landscape research to landscape planning" because we observed that many of the current research activities on landscape are located somewhere between pure landscape research and landscape planning. The aim of this book is to illustrate how we can integrate different disciplines in landscape research and to examine the concrete experiences of $\mathrm{PhD}$ students involved in the process of integrative landscape research.

\section{A PhD student's perspective on integrative landscape research and landscape planning}

In June 2004, we organized a one-week PhD master class on "Integrative research for the planning and management of sustainable landscapes" to help $\mathrm{PhD}$ students cope with the increasing demands of integrative landscape research. The $30 \mathrm{PhD}$ students who participated in the international $\mathrm{PhD}$ master class were selected from a group of 60 applicants. All selected students were involved in $\mathrm{PhD}$ projects on landscape issues and had chosen to apply integrative approaches for their studies. The PhD students had diverse backgrounds in landscape-related fields such as landscape ecology, landscape architecture, sociology, natural-resource management, environmental studies, landscape planning, engineering, geography, agricultural sciences, forestry, policy studies, ecology, biology, nature conservation, and history. Twenty of the students were female, ten male. Most of them were in the first or second year of their $\mathrm{PhD}$ study. Ten students were near completion of their $\mathrm{PhD}$ study and planned to submit their work either in the same year as the course or in the following year.

At the outset of the master class, all $\mathrm{PhD}$ students received a short questionnaire to survey the students' perspective on integrative research in relation to their own $\mathrm{PhD}$ project. The aim of the survey was to get an overview on the students' experiences with integrative research concepts and to let them reflect on problems and limitations of these concepts in relation to their own projects. This reflection stimulated the further discussion on integrative research during the master class. It also reflected some of the key challenges students faced in their studies. The most important challenges identified were addressed directly at the course and are also discussed in this book. The questionnaire comprised five questions that were answered within 30 minutes by each student. All answers were recorded anonymously. Each questionnaire was assigned a code (PhD-01, PhD-02, PhD-03 etc.) for internal identification.

\section{Survey results}

The first question we asked was "How would you define interdisciplinarity and transdisciplinarity?”. The answers were very diverse. Some responses reflected literature readings, others practical experiences. Some respondents had probably not thought in depth about the terms before. Some selected examples of the answers are presented in Table 1, split into interdisciplinarity and transdisciplinarity. 
Table 1. Selected examples of postgraduates' understandings of interdisciplinarity and transdisciplinarity

\begin{tabular}{|c|c|c|}
\hline No. & Postgraduate's statement & Code \\
\hline \multicolumn{3}{|c|}{ Interdisciplinarity: } \\
\hline 1 & $\begin{array}{l}\text { "researchers stay in their own disciplines but engage with others } \\
\text { outside their disciplines to find integrated solutions" }\end{array}$ & $(\mathrm{PhD}-01)$ \\
\hline 2 & $\begin{array}{l}\text { "several disciplines study a subject separately and at the end a } \\
\text { synthesis is made" }\end{array}$ & $(\mathrm{PhD}-10)$ \\
\hline 3 & "when scientists combine disciplines in their research generally" & $(\mathrm{PhD}-11)$ \\
\hline 4 & "working together but keeping to own disciplinary boundaries" & $(\mathrm{PhD}-12)$ \\
\hline 5 & $\begin{array}{l}\text { "a phase when experts from different fields research the same } \\
\text { topic" }\end{array}$ & $(\mathrm{PhD}-13)$ \\
\hline 6 & $\begin{array}{l}\text { "the different disciplines might use each other's results, but arrive } \\
\text { at their own disciplinary conclusions and answers" }\end{array}$ & $(\mathrm{PhD}-14)$ \\
\hline 7 & $\begin{array}{l}\text { "different subjects working together without crossing borders of } \\
\text { subjects - more of academic use" }\end{array}$ & $(\mathrm{PhD}-17)$ \\
\hline \multicolumn{3}{|c|}{ Transdisciplinarity: } \\
\hline 8 & $\begin{array}{l}\text { "is evolving from two or more disciplines merging into a new } \\
\text { scientific field" }\end{array}$ & $(\mathrm{PhD}-02)$ \\
\hline 9 & $\begin{array}{l}\text { "a project that is interdisciplinary in nature and which also } \\
\text { includes a public input component" }\end{array}$ & $(\mathrm{PhD}-04)$ \\
\hline 10 & $\begin{array}{l}\text { "several disciplines define a goal for their work and exchange } \\
\text { information while developing the project. The result is integrated" }\end{array}$ & $(\mathrm{PhD}-10)$ \\
\hline 11 & "when a concrete problem is solved using different disciplines" & $(\mathrm{PhD}-11)$ \\
\hline 12 & $\begin{array}{l}\text { "different disciplines work on the same question. } \\
\text { Transdisciplinary research will thus arrive at an answer or } \\
\text { solution, which could not be achieved by only one discipline" }\end{array}$ & $(\mathrm{PhD}-14)$ \\
\hline
\end{tabular}

The second question was "Where on a scale from a disciplinary approach to high integration is your PhD project placed? (Scale from 1 to 5 , where $1=$ disciplinary and 5 = integrative)". The mean score of all answers was 3.52 with a variance from 2 to 5 . No student considered his/her own project as disciplinary. Three students had placed their own project on the scale as 5 (integrative).

The third question was "What was your motivation to choose an integrative approach in your PhD project?”. Here, the PhD students expressed different reasons for being engaged in integrative research such as personal interest, belief that results will be more useful, availability of funds, type of study object demanding such an approach, societal demand, and the offer to join a larger project. Selected examples of the responses are shown in Table 2.

The fourth question was "How do you think your results will differ from those of a disciplinary perspective?”. These statements were very diverse as shown in Table 3. Some respondents did not know what difference to expect by applying an integrative instead of a disciplinary approach. Other respondents expressed the potential for greater applicability of results, especially in a planning context, whereas others acknowledged that integrative results might lose depth in favour of breadth. 


\section{Chapter 1}

Table 2. Selected examples of postgraduates' motivations for applying integrative approaches in their $\mathrm{PhD}$ projects

\begin{tabular}{|c|c|c|}
\hline No. & \begin{tabular}{|l|} 
Postgraduate's statement \\
\end{tabular} & Code \\
\hline 1 & $\begin{array}{l}\text { "I enjoy the challenge of inter/transdisciplinary research and problem- } \\
\text { solving" }\end{array}$ & $(\mathrm{PhD}-01)$ \\
\hline 2 & $\begin{array}{l}\text { "I think the combination of the two approaches [interdisciplinarity and } \\
\text { transdisciplinarity] will create new knowledge. The objects of my study } \\
\text { have not been studied in this way before" }\end{array}$ & $(\mathrm{PhD}-03)$ \\
\hline 3 & $\begin{array}{l}\text { "Strong feeling that things that really matter cannot be talked about, if } \\
\text { some integration is not taking place" }\end{array}$ & $(\mathrm{PhD}-06)$ \\
\hline 4 & $\begin{array}{l}\text { "I believe we can achieve more useful results for an actual rural } \\
\text { development” }\end{array}$ & $(\mathrm{PhD}-08)$ \\
\hline 5 & $\begin{array}{l}\text { "I am interested in sustainability issues and one cannot study } \\
\text { sustainability without an integrative approach" }\end{array}$ & $(\mathrm{PhD}-11)$ \\
\hline 6 & $\begin{array}{l}\text { "I am not sure whether my approach is really integrative. However, } \\
\text { when studying such complex issues like landscape dynamics, I think it } \\
\text { is crucial to use approaches from different scientific disciplines" }\end{array}$ & $(\mathrm{PhD}-14)$ \\
\hline 7 & $\begin{array}{l}\text { "A combination of chance and funding potentials and increasing sense } \\
\text { that crossing perceived disciplinary boundaries and integrating } \\
\text { knowledge cultures makes for fruitful research" }\end{array}$ & $(\mathrm{PhD}-15)$ \\
\hline 8 & $\begin{array}{l}\text { "Since I want to understand what is going on in my case study area in } \\
\text { terms of land-use changes, it is obvious for me to talk with the people } \\
\text { who are dealing with it" }\end{array}$ & $(\mathrm{PhD}-21)$ \\
\hline 9 & $\begin{array}{l}\text { “Simple disciplinary approaches are not suitable to face 'real world' } \\
\text { problems” }\end{array}$ & $(\mathrm{PhD}-23)$ \\
\hline 10 & $\begin{array}{l}\text { "I was asked to participate in a project that was interdisciplinary } \\
\text { already" }\end{array}$ & $(\mathrm{PhD}-24)$ \\
\hline
\end{tabular}

In the last question we asked "What are the three biggest challenges for you as a $\mathrm{PhD}$ student in achieving integration?”. Two clear groups of answers could be identified. The first group included challenges that are related to the subject of the study as well as to methodological or epistemological constraints. The second group included challenges that were related to infrastructure, supervision, merit, recognition by colleagues and other more practical issues. Two students perceived "completing the $\mathrm{PhD}$ ” itself as one of the biggest challenges. Selected examples of responses are shown in Table 4. 
Table 3. Selected examples of postgraduates' expectations towards differences between results deriving from a disciplinary and integrative perspective

\begin{tabular}{|c|c|c|}
\hline No. & Postgraduate's statement & Code \\
\hline 1 & $\begin{array}{l}\text { "By using an interdisciplinary approach it should be possible to use } \\
\text { more and different sources and to give my project a planning } \\
\text { dimension which would be impossible without an integrated } \\
\text { approach" }\end{array}$ & $(\mathrm{PhD}-03)$ \\
\hline 2 & "I don’t know” & $(\mathrm{PhD}-05)$ \\
\hline 3 & "I will go deeper into the causes of the issues I address" & $(\mathrm{PhD}-10)$ \\
\hline 4 & $\begin{array}{l}\text { "I think you can see a problem more clearly if you try to look at it } \\
\text { from different perspectives or points of view" }\end{array}$ & $(\mathrm{PhD}-13)$ \\
\hline 5 & "In attempting breadth I may lose some depth” & $(\mathrm{PhD}-15)$ \\
\hline 6 & $\begin{array}{l}\text { "The disciplinary perspective is more concerned with theories and } \\
\text { paradigms. My research however would (hopefully) be more practical } \\
\text { and produce applicable knowledge to everyday conservation" }\end{array}$ & $(\mathrm{PhD}-16)$ \\
\hline 7 & "I hope they will be useful for practical use" & $(\mathrm{PhD}-17)$ \\
\hline 8 & $\begin{array}{l}\text { "Integrative research is more complex and thus more applicable in } \\
\text { practice and for land users" }\end{array}$ & $(\mathrm{PhD}-19)$ \\
\hline 9 & $\begin{array}{l}\text { "Less reliability and validity of results in a strongly scientific } \\
\text { understanding" }\end{array}$ & $(\mathrm{PhD}-23)$ \\
\hline 10 & "Gives answers and questions that are more demanded by society" & $(\mathrm{PhD}-24)$ \\
\hline
\end{tabular}

Table 4. Selected examples of biggest challenges for postgraduates in achieving integration

\begin{tabular}{|c|c|c|}
\hline No. & Postgraduate's statement & Code \\
\hline 1 & $\begin{array}{l}\text { "lack of supervisory expertise in crossdisciplinary research, lack of } \\
\text { established methodologies, isolation from other researchers with } \\
\text { similar projects" }\end{array}$ & $(\mathrm{PhD}-01)$ \\
\hline 2 & $\begin{array}{l}\text { "getting understanding and acceptance from other disciplines or people } \\
\text { with a more 'classical' background" }\end{array}$ & $(\mathrm{PhD}-05)$ \\
\hline 3 & $\begin{array}{l}\text { "how to formalize indigenous/local knowledge into 'universal' } \\
\text { academic language and vice versa” }\end{array}$ & $(\mathrm{PhD}-06)$ \\
\hline 4 & $\begin{array}{l}\text { "making others realize the benefits of integration; how to behave in } \\
\text { integrated work in order to avoid competition among team members; } \\
\text { adapting to each other's language and priorities" }\end{array}$ & $(\mathrm{PhD}-10)$ \\
\hline 5 & $\begin{array}{l}\text { "to be sufficiently persuasive to attract the attention and the } \\
\text { understanding of planners" }\end{array}$ & $(\mathrm{PhD}-18)$ \\
\hline 6 & “to complete” & $(\mathrm{PhD}-20)$ \\
\hline 7 & "reaching depth" & $(\mathrm{PhD}-22)$ \\
\hline 8 & $\begin{array}{l}\text { "focusing on really important aspects and not losing myself in all the } \\
\text { possibilities" }\end{array}$ & $(\mathrm{PhD}-23)$ \\
\hline 9 & $\begin{array}{l}\text { "the limitations of my own mind! And time to get into the minds } \\
\text { (concepts and language) of the other participants" }\end{array}$ & $(\mathrm{PhD}-24)$ \\
\hline
\end{tabular}




\section{Key challenges}

The analysis of the $\mathrm{PhD}$ students' responses, the discussions at the course and experiences from similar courses have revealed several challenges facing $\mathrm{PhD}$ students when involved in integrative landscape research.

1. Terminology: The understanding of terms such as 'interdisciplinary', 'transdisciplinary' and 'integrative' is obviously not clear. PhD students use the approaches in different ways, which is not exceptional because established researchers do the same. The consequences of such use are that communication and exchange of knowledge about integrative concepts is difficult and sometimes impeded (Tress, Tress and Fry 2005b; in press).

2. Epistemology: How is it possible to integrate different disciplines, e.g. from social sciences and natural sciences? This is a crucial question because $\mathrm{PhD}$ students might act as mediator between different research cultures. The theoretical and methodological toolkit to tackle the epistemological challenge is still very limited.

3. Expectations: High expectations are placed on the integration process, either by the researchers themselves or by society. PhD students acknowledge that their research needs to be useful and applicable to solve 'real world' problems. However, expectations may be far too high to be achieved within a $\mathrm{PhD}$ project. Sometimes, the aspect of solving real-world problems is put in the fore at the cost of knowledge production and contribution to progress in science.

4. Stakeholder involvement: The involvement of stakeholders and the general public is another challenge to $\mathrm{PhD}$ students in integrative landscape projects. To what degree should stakeholders be involved and which role do they have in a project?

5. Organization: Organizational and institutional limitations make it difficult to facilitate the integration process. PhD students are isolated from each other, lack competent supervision, face time pressure and fear getting lost in the expectations of considering too many aspects at the same time.

6. Communicating and publishing: Communication across disciplinary boundaries is more difficult, but becomes crucial when doing integrative landscape research. Publishing is expected from $\mathrm{PhD}$ students and an important aspect of their future academic careers, but remains a major problem.

\section{The structure of this book}

The aim of the contributions in this book is to help overcome the challenges and barriers identified. The book offers guidelines for $\mathrm{PhD}$ students to cope with the challenges of a doctorate in integrative landscape research and to find their own role in integrative research. The book is structured in four parts dealing with (i) the development of integrative theory and concepts; (ii) the development of integrative tools and methods; (iii) training and education for integration; and (iv) the application of integrative concepts in landscape research.

The first part deals with the development of integrative theory and concepts. This part proposes a clarification of terminology of concepts with the aim to support effective communication on and application of integrative concepts. It addresses the application and meaning of the landscape concepts in different academic domains and introduces the emerging domain of transdisciplinary landscape sciences.

In the second part, the chapters present tools and methods that help facilitate integration in landscape research and planning and especially discuss the challenges of stakeholder involvement in landscape research. The chapters illustrate what kind of tools and methods can help to achieve integration in landscape studies. 
In the third part, the chapters discuss the educational premises and training needs for integration, present strategies for successful communication in integrative projects, suggest key steps to cope successfully with the challenges of integration and project organization, and present guidelines for publishing a research paper from integrative research.

In the fourth part, application of integrative concepts, the ten chapters exemplify ways to approach successful integration in $\mathrm{PhD}$ projects.

The book closes with presenting strategies for $\mathrm{PhD}$ students to survive in integrative landscape research. Through this, we wish to stimulate the exchange of practical and theoretical ideas on integrative research among postgraduate students and encourage them to further develop and apply strategies to cope with the challenges they face from an early stage in their study.

\section{Acknowledgements}

We thank the PhD students at the course for participating in the survey.

\section{References}

Antrop, M., 2000. Geography and landscape science. Belgian Journal of Geography. Belgeo special issue. 29th International Geographical Congress (1/4), 9-35.

Bender, B., 1993. Landscape: meaning and action. In: Bender, B. ed. Landscape, politics, and perspectives. Berg, Oxford, 1-17.

Cosgrove, D., 2003. Landscape: ecology and semiosis. In: Palang, H. and Fry, G. eds. Landscape interfaces: cultural heritage in changing landscapes. Kluwer Academic Publishers, Dordrecht, 15-20. Landscape series vol. 1.

Council of Europe, 2000. European landscape convention. Council of Europe. [http://www.coe.int/t/e/Cultural_Co-operation/Environment/Landscape/]

Décamps, H., 2000. Demanding more of landscape research (and researchers). Landscape and Urban Planning, 47 (3/4), 105-109.

Di Castri, F., 1997. Editorial: Landscape ecology in a changing globalized environment. Landscape Ecology, 12 (1), 3-5.

Fry, G., Tress, B. and Tress, G., 2004. The potential and limitations of integrated grassland research. In: Lüscher, A., Jeangros, B., Kessler, W., et al. eds. Land use systems in grassland dominated regions: proceedings of the 20th general meeting of the European Grassland Federation, Luzern, Switzerland, 21-24 June 2004. vdf Hochschulverlag AG an der ETH Zürich, Zürich, 1157-1167. Grassland Science in Europe no. 9.

Hobbs, R.J., 1997. Future landscapes and the future of landscape ecology. Landscape and Urban Planning, 37, 1-9.

Muir, R., 1999. Approaches to landscape. MacMillan Press, London.

Naveh, Z., 1995. Interactions of landscapes and cultures. Landscape and Urban Planning, 32 (1), 43-54.

Pickett, S.T.A., Cadenasso, M.L. and Grove, J.M., 2004. Resilient cities: meaning, models, and metaphor for integrating the ecological, socio-economic, and planning realms. Landscape and Urban Planning, 69 (4), 369-384.

Sancar, F.H., 1993. An integrative approach to public participation and knowledge generation in design. Landscape and Urban Planning, 26, 67-88. 
Chapter 1

Toth, R.E., 1988. Theory and language in landscape analysis, planning, and evaluation. Landscape Ecology, 1 (4), 193-201.

[http://landscape.forest.wisc.edu/landscapeecology/Articles/V01I04P193.pdf]

Tress, B. and Tress, G., 2001. Capitalising on multiplicity: a transdisciplinary systems approach to landscape research. Landscape and Urban Planning, 57 (3/4), 143-157.

Tress, B., Tress, G. and Fry, G., 2005a. Defining concepts and the process of knowledge production in integrative research. In: Tress, B., Tress, G., Fry, G., et al. eds. From landscape research to landscape planning: aspects of integration, education, and application. Springer, in this volume.

Tress, B., Tress, G. and Fry, G., 2005b. Integrative studies on rural landscapes: policy expectations and research practice. Landscape and Urban Planning, 70 (1/2), 177-191.

Tress, G., Tress, B. and Fry, G., in press. Clarifying integrative research concepts in landscape ecology. Landscape Ecology. 